\title{
Gas Distribution Benchmarking of Utilities from Slovenia, the Netherlands and the UK: an Application of Data Envelopment Analysis
}

Jelena Zorić, Nevenka Hrovatin, Gian Carlo Scarsi*

Abstract:

This paper carries out non-parametric relative efficiency comparisons using an international sample of gas distribution utilities from two old and one new EU members, namely the Netherlands, the UK, and Slovenia. By conducting DEA on a cross-sectional sample of gas utilities, we discover that, on average, Slovenian utilities perform less efficiently than UK and Dutch utilities. To a large extent, this is due to the less extensive regulation of the Slovenian gas industry as seen in the past. The incentive-based price-cap regulation recently introduced in Slovenia could help close this efficiency gap over time. The authors also find out that different model specifications lead to very similar efficiency scores and rankings, implying that benchmarking can be employed as a useful complementary instrument for monitoring utility performance. In this way, the informational asymmetry between distribution utilities and regulatory authorities can be significantly mitigated. For the wider and more successful implementation of international benchmarking in the future, it is also important that coherent regional and international data is made available to regulators.

Key words: price regulation, international benchmarking, comparative efficiency analysis, DEA, gas distribution utilities

JEL: C61, D24, L51, L95

\section{Introduction}

In 1998, the European Commission (EC) introduced a Gas Directive (98/30/EC) with the aim to reduce gas prices, boost economic efficiency, and promote gas-togas competition. In the EU's view, greater competition in the area of energy-related activities should contribute to lower operating costs and to strengthening the competitiveness of EU economies. The Gas Directive set the general rules for the internal natural gas market. Key points of the directive were the gradual and progressive opening up of the natural gas market, the abolition of exclusive rights, the introduction of non-discriminatory access to the gas network, and the unbundling of internal utility accounts. On 26 June 2003, the EU passed a new Gas Directive (2003/55/EC), which resulted in further liberalisation of the market. The new Gas Directive
DOI: 10.2478/v10033-009-0008-1

requires that: (a) all non-household customers become eligible by 1 July 2004 and all customers become eligible by 1 July 2007; (b) regulated third-party access

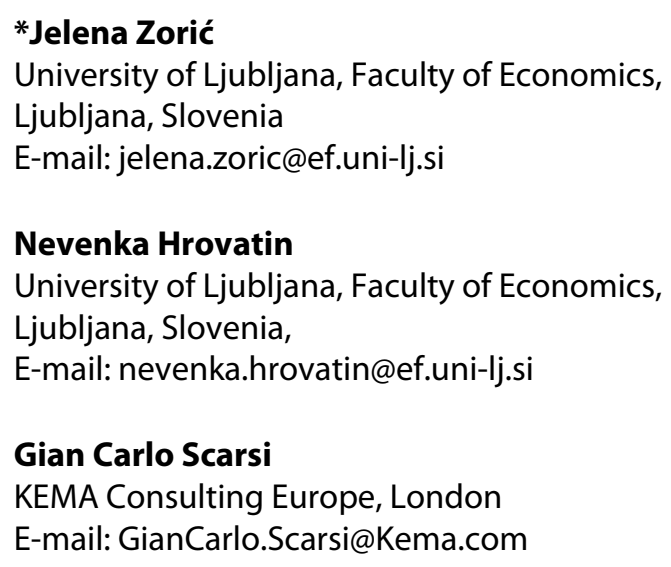


(rTPA) is implemented; (c) a regulatory body is empowered; and (d) rigorous demands for the separation of TSO (Transmission System Operator) and DSO (Distribution System Operator) activities are imposed on natural gas market participants.

As transmission and distribution activities remain regulated due to their natural monopoly character, liberalisation of the gas sector is typically combined with a (re-) regulation of the use of network prices. Regulatory authorities around the world have adopted a variety of approaches to regulate distribution prices. The most common incentive-based schemes are based on price capping, revenue capping, yardstick regulation, and various benchmarking methods.' Under price capping, prices are set in advance for a period of (generally) three to five years, thus allowing the firm to benefit from any cost savings made during that period, but they are recalculated at regular intervals in order to bring them back in line with underlying costs. The price cap (RPI-X) usually allows the utility to increase its overall price level by a yearly rate of inflation, as measured by the previous year's Retail Price Index (RPI), minus a percentage efficiency factor (X) that reflects the real cost reduction expected by the regulator.

However, due to the imperfect information available to the regulator, there are some problems with price cap regulation because the regulator does not know a firm's true costs. High costs may be due to either a firm's particular production situation or to sheer inefficiency. Thus, if price caps are set too high, there is the possibility of a welfare loss while, if they are too low, firms might encounter financial viability problems. In setting the initial price level and the yearly efficiency factor $X$ in price cap regulation, the regulator can use some form of cost-based benchmarking. In this case, benchmarking is used to establish a larger information basis for more effective price cap regulation that reduces the informational asymmetry between firms and regulators. Frontier-based benchmarking methods identify or estimate the efficient performance frontier from sample best practice. The efficient frontier is then a benchmark against which the relative performance of all firms is measured. In the case of small countries, international benchmarking appears to be particularly advantageous since a limited number of firms tend to operate in each sector. International comparisons also enable regulators to measure efficiency relative to international best practice.

In this paper we compare the performance of gas distribution utilities from the Netherlands, the UK, and Slovenia. International benchmarking is conducted using Data Envelopment Analysis (DEA), which is a non-parametric (linear programming) frontier benchmarking method. One of our main aims is to ascertain whether relative efficiency differences are demonstrable for gas distribution utilities between one of the EU's newcomers and two of the most established EU member states. To the authors' knowledge, this is one of the first studies on international gas benchmarking, as opposed to the more traditionally explored area of electricity distribution.i The slower pace of liberalisation in the market for natural gas and its less extensive regulation as a result of the traditional principle of negotiated third-party access may explain the relative novelty of gas distribution benchmarking.

\section{Gas Distribution in the UK, the Netherlands and Slovenia}

Gas distribution in the three countries examined differs both at an average size and an ownership level. In the UK, gas distribution has been traditionally linked to gas transmission and has been provided jointly by Transco, formerly part of British Gas, the integrated gas monopolist privatised in 1986 by Margaret Thatcher's government. At the beginning of the current decade, Transco underwent some further transformation after its more or less passive incorporation into the National Grid Company of electricity to form the new corporate bundle that is today known as National Grid/Transco (NGT). NGT is in mixed private ownership of UK and international investors. The previous Gas Area Boards, known under Transco as Local Distribution Zones, have been partially disentangled from the main NGT structure in 2004: four out of eight were sold off (Scotland, Wales and West, North of England, and South of England) to national and international investors, some of whom were electricity companies or 
other utilities. The average size of a UK Local Distribution Zone is much larger than that of any other firm in our sample as British gas distribution companies tend to cover entire bundles of counties. On 1 April 2002, the UK's gas distribution sector became subject to a separate five-year price control formula (RPI-X), as distinct from the gas transmission formula. From 1 April 2004, this single distribution price control formula was disaggregated into eight separate formulae (network price control formulae) to cover the activities of the eight regional gas distribution networks (NGT 2005).

Gas distribution in the Netherlands has undergone a restructuring process after the liberalisation of the sector was pushed forward in the early nineties with some delays as opposed to the liberalisation of electricity, which were mainly due to political opposition and the strong corporate entrenchment of some of the actors in the market. At the beginning of the decade, the number of county-based and municipal gas distributors in the Netherlands totalled around 25, although this figure is bound to decrease as a result of the possibility of mergers reaching the gas industry after having already touched the electricity networks sector. All of the Dutch gas distributors are controlled by public owners in the form of (mainly) local and county councils, although privatisation might be on the political agenda at some stage in the not too distant future. However, the smaller companies will be likely to stay in public ownership for some foreseeable time to come. The Dutch regulator DTE has imposed price-capping (CPI-X regulation) since 2002, where efficiency objectives (X-factors) of the individual companies were determined by means of the benchmarking of total expenditure being made up of operating and capital costs. The regulatory formula being chosen is in line with the equivalent form of regulation adopted in the electricity distribution industry. In the Dutch benchmarking analysis of gas distribution utilities, DEA was chosen as the official benchmarking method (DTE 2001).

As regards Slovenia, the natural gas transmission network is owned and operated by former gas monopolist Geoplin. Until early 2003, Geoplin enjoyed a monopoly on import, transportation, and transit of natural gas throughout Slovenia.iii Today there are 17 local distribution utilities that distribute natural gas to households, small industry, and commercial users in more than 60 municipalities. ${ }^{i v}$ End natural gas users in Slovenia are supplied via both the transport and local distribution networks. ${ }^{v}$ The ownership structure of gas distribution companies is quite diverse: six companies are majority-owned by one or more municipalities, seven of them are majority owned by domestic private investors, two of them are majority owned by foreign private investors, and one company does not have a majority owner (AERS 2005a). To comply with the EU legislation, namely the Gas Directives (98/30/EC) and (2003/55/EC), Slovenia had to adopt the Energy Act (1999) and the amended Energy Act (2004). Therefore, the process of liberalisation of the Slovenian natural gas market to a large extent resembles what other EU countries were witnessing. The natural gas market in Slovenia has been opened for eligible customers at the beginning of 2003. After the amended Energy Act (2004) was passed, all customers except for households became eligible as of 1 July, 2004. Accordingly, the percentage of eligible customers in the Slovenian gas market rose from 50\% in 2003 to $90.4 \%$ in 2004 (AERS 2005a).vi On 1 July 2007 the Slovenian natural gas market fully opened, while in the UK and the Netherlands the market has been fully liberalised several years before. In Slovenia, the amended Energy Act (2004) furthermore introduced regulated TPA, which replaced negotiated TPA for access to transmission and distribution networks. Economic regulation of network charges for distribution networks is based on the price-cap methodology (CPI$\mathrm{X}$ ). To assess and allow eligible costs, the Energy Agency of the Republic of Slovenia (AERS) intends to conduct benchmarking of controllable operating costs using both domestic and foreign gas distribution comparators by means of DEA. The starting regulatory period has been originally set to be the two-year lag 2006-2007. Finally, it has been decided that the regulatory period should be one year only (AERS 2005b). 


\section{Methodology}

There has always been a close link between the measurement of efficiency and the use of frontier functions, which are used as standards against which to measure a firm's efficiency. Modern efficiency measurement begins with Farrell (1957), who drew on the work of Debreu (1951) and Koopmans (1951) to define a simple measure of firm efficiency that could account for multiple inputs and easily generalise to multiple outputs. Efficiency measures typically assume that the production or cost function of the fully efficient, or 'best-practice', firm is known. However, this is rarely the case, meaning that the production or cost frontier must be estimated or constructed from sample data. Different techniques can be utilised: one of the ways to obtain the frontier and corresponding firms' efficiency scores is via Data Envelopment Analysis.

DEA entails the use of linear programming methods to calculate (rather than estimate) a non-parametric piece-wise efficient frontier. Firms that make up the frontier encompass the less efficient firms. Efficiency measures are then calculated relative to this frontier. The relative efficiency score of the firm is calculated on a scale of 0 to 1 , with the frontier firms receiving a score of 1. DEA models can be either input or output oriented, and can be specified according to either constant returns to scale (CRS) or variable returns to scale (VRS). DEA with constant returns to scale was introduced by Charnes, Cooper and Rhodes (1978), while in Banker, Charnes and Cooper (1984) variable returns to scale are assumed. Output-oriented models maximise the output vector for a given amount of inputs, while input-oriented models minimise the input vector for a given level of outputs. Given that most distribution utilities have an obligation to meet demand, they can only become more efficient by providing a predefined output level with fewer inputs. We will therefore use an input-orientation approach in what follows.

Assume there is information on $K$ inputs and $M$ outputs for each of $N$ firms. For the $i$-th firm, these are represented by the column vectors $\mathbf{x}_{\mathbf{i}}$ and $\mathbf{y}_{\mathbf{i}}$, respectively. The $K \times N$ input matrix $\mathbf{X}$ and $M \times N$ output matrix $\mathbf{Y}$ represent the data for all $N$ firms. The linear programme of input-oriented CRS envelopment model is formulated as follows: vii

$$
\begin{array}{ll}
\min _{\theta, \lambda} \theta & \\
\text { st } \quad-\mathbf{y}_{\mathbf{i}}+\mathbf{Y} \boldsymbol{\lambda} \geq 0 \\
\\
\theta \mathbf{x}_{\mathbf{i}}-\mathbf{X} \boldsymbol{\lambda} \geq 0 \\
\boldsymbol{\lambda} \geq 0,
\end{array}
$$

where $\theta$ is a scalar and $\lambda$ is a $N \times 1$ vector of constants. The value of $\theta$ obtained will represent the technical efficiency score (TE) of the $i$-th firm. The linear programming problem must be solved $N$ times, once for each firm. Essentially, the problem takes the $i$-th firm and then seeks to radially contract the input vector $\mathbf{x}_{\mathbf{i}}$ as much as possible, while still remaining within the feasible input set. The inner-boundary of this set is a piece-wise linear isoquant, determined by the observed data points. Since $\theta$ is a feasible solution to (1), the optimal value $\theta \leq 1$. If $\theta=1$, the current input levels can no more be proportionally reduced, indicating that a firm is on the frontier. Otherwise, if $\theta<1$, then the firm is dominated by the frontier.

DEA can also accommodate 'environmental' or nondiscretionary variables. These variables are beyond managerial control but still affect the efficiency of the firm. For example, for regulated distribution utilities the size of the service area, population density, and peak demand are supposedly exogenous factors. Assume there are $L$ environmental variables to be added to the model, denoted by the $L \times 1$ vector $\mathbf{z}_{\mathbf{i}}$ for the $i$-th firm, and $L \times N$ matrix $\mathbf{Z}$ for the full sample. Environmental or non-discretionary variables can be introduced through an additional set of constraints to the model sub (1) as input (a), output (b), or as 'neutral' variables (c):

a) $\mathbf{z}_{\mathbf{i}}-\mathbf{Z} \lambda \geq 0$,

b) $\mathbf{z}_{\mathbf{i}}-\mathbf{Z} \boldsymbol{\lambda} \leq 0$,

c) $\mathbf{z}_{\mathbf{i}}-\mathbf{Z} \boldsymbol{\lambda}=0$.

If one is unsure about the direction of the influence of environmental variables, then these variables can be included in the linear programming problem as neutral variables (Coelli, Rao and Battese 1998).

In the VRS DEA model, a convexity constraint is added to (1): 


$$
\sum_{i=1}^{N} \lambda_{i}=1
$$

This additional constraint ensures that the firm is compared with other firms of a similar size. When not all the firms are operating at the optimal scale, then technical efficiency as calculated by the constant returns to scale model ( $T E_{C R S}$ ) will include 'pure' technical efficiency ( $\left.T E_{V R S}\right)$ as well as scale efficiency $(S E)$ :

$$
T E_{C R S}=T E_{V R S} \times S E \text {. }
$$

By conducting both CRS and VRS DEA, one can obtain a scale efficiency measure for each firm.

Technical efficiency is a necessary, but not a sufficient condition for achieving cost efficiency. It may be the case that a technically efficient firm uses inappropriate mixes of inputs given the relative prices it faces. If price information is available and a behavioural objective, such as cost minimisation, is appropriate, then it is possible to measure technical efficiency (TE) as well as allocative efficiency $(A E)$. Hence, the measure of cost efficiency $(C E)$ is defined as:

$$
C E=T E \times A E \text {. }
$$

Cost efficiency has the property of multiplicative separability into input-allocative and technical efficiencies. $^{\text {viii }}$ All three efficiency measures are bounded between 0 and 1 . A firm is cost-efficient if and only if it is both technically and allocatively efficient. Cost efficiency is obtained by solving the following linear program:

$$
\begin{gathered}
\min _{\lambda, \mathbf{x}_{\mathbf{i}}^{*}} \mathbf{w}^{\mathrm{T}} \mathbf{x}_{\mathbf{i}}^{*} \\
\text { s.t. } \quad-\mathbf{y}_{\mathbf{i}}+\mathbf{Y} \boldsymbol{\lambda} \geq 0 \\
\mathbf{x}_{\mathbf{i}}^{*}-\mathbf{X} \boldsymbol{\lambda} \geq 0 \\
\boldsymbol{\lambda} \geq 0,
\end{gathered}
$$

where $\mathbf{w}$ is a strictly positive $K \times 1$ vector of input prices and $\mathbf{x}_{\mathbf{i}}^{*}$ is the cost minimising vector of inputs for the $i$-th firm, given input prices $\mathbf{w}$ and output levels $\mathbf{y}_{\mathbf{i}}$. The total cost efficiency of the $i$-th firm is calculated as the ratio of minimum to observed cost:

$$
C E=\mathbf{w}_{\mathbf{i}}^{\mathrm{T}} \mathbf{x}_{\mathbf{i}}^{*} / \mathbf{w}_{\mathbf{i}}^{\mathrm{T}} \mathbf{x}_{\mathbf{i}} .
$$

The input-allocative measure of efficiency can be then obtained residually using (5).
A central aspect of DEA is the choice of appropriate input and output variables. The variables should reflect the main aspects of resource use in the activity concerned. DEA does not require the specification of a cost or production function. However, efficiency scores tend to be sensitive to the choice of input and output variables. Also, as more variables are included in the model, the number of firms on the frontier increases. Further, the method does not allow for stochastic factors and measurement error.

An alternative to the DEA would be to employ parametric (statistical) frontier methods, namely Corrected Ordinary Least Squares (COLS) and Stochastic Frontier Analysis (SFA). They typically require a cost function to be specified. Similarly to the DEA, a drawback of the COLS method is that it does not allow for stochastic errors and relies heavily on the position of a single most efficient unit. In contrast, the SFA method allows the inclusion of a stochastic error. However, it makes strong assumptions on the distribution of both the errors and the inefficiency term. ${ }^{\text {ix }}$ The SFA method is therefore not particularly recommended in the presence of small samples. As this is the case in our study, we decided to conduct the analysis by employing the DEA. DEA is also the preferred choice made by many energy regulators that use benchmarking in price regulation (e.g., the Dutch regulator DTE, the Norwegian regulator NVE and the Austrian regulator $\mathrm{E}$-Control).

Despite extensive research carried out in the field of efficiency measurement, so far there is no consensus in the academic literature on which method has been found to perform the best. Since the various benchmarking methods may lead us to different results, and none of the methods has been proven to be superior with respect to the others, it is important to be aware of the advantages and disadvantages of applying the different benchmarking approaches to measure a firm's performance. In addition, it is important to examine the sensitivity of the efficiency scores and rank orders to model specification. ${ }^{x}$ 


\section{Data and Model Description}

Regulators can use cross-country benchmarking in order to evaluate the performance of domestic utilities within the larger context of international practice. So far, only a few regulators have applied international benchmarking methods. The most relevant difficulty with international comparisons regards the comparability, quality, and availability of data. Since the heterogeneity of firms in an international framework is wider, quality of data is even more important than in national comparisons. The data should adequately represent different types and sizes of utilities, and should take into account differences in technical standards, accounting principles, and environmental characteristics. Further, when comparing monetary units, the correct handling of currency exchange rates is particularly significant. Purchasing power parity units (PPP) are normally used in order to correct for international differences in relative prices. Relative differences in input prices beyond the control of the firm could also be considered (e.g. wage rates, taxes, and rates of return on capital). These issues can only be tackled in time and through closer co-operation between regulators (Jamasb and Pollitt 2001).

\section{Sample and variables}

The international gas benchmarking based on the operating expenditure of distribution and supply activities is performed using a sample of 42 gas distribution utilities in the year 2003 from: ${ }^{\text {xi }}$

- Slovenia (SLO): 14 companies;

- The Netherlands (NL): 21 companies; and

- The United Kingdom (UK): 7 companies.

The following variables were used in the comparative efficiency analysis:

1. operating expenditure of gas distribution and supply activities (OPEX, in EUR, PPP-adjusted);

2. number of customers (CUST);

3. gas throughput supplied (OUTPUT, in cubic metres);

\begin{tabular}{|c|c|c|c|c|c|c|}
\hline Variable & Country & $\mathbf{N}$ & Mean & Std. Dev. & Minimum & Maximum \\
\hline \multirow{4}{*}{$\begin{array}{l}\text { OPEX } \\
\text { (thousands } \\
\text { EUR, PPP) }\end{array}$} & UK & 7 & 261,909 & 68,197 & 192,859 & 398,103 \\
\hline & $\mathrm{NL}$ & 21 & 24,698 & 28,472 & 3,395 & 97,594 \\
\hline & SLO & 14 & 1,747 & 2,260 & 76 & 8,418 \\
\hline & Total & 42 & 56,583 & 99,111 & 76 & 398,103 \\
\hline \multirow{4}{*}{$\begin{array}{l}\text { CUST } \\
\text { (number of } \\
\text { customers) }\end{array}$} & UK & 7 & $2,447,224$ & 691,968 & $1,671,850$ & $3,835,972$ \\
\hline & $\mathrm{NL}$ & 21 & 209,589 & 239,729 & 17,993 & 915,270 \\
\hline & SLO & 14 & 6,478 & 14,708 & 6 & 54,172 \\
\hline & Total & 42 & 514,824 & 933,635 & 6 & $3,835,972$ \\
\hline \multirow{4}{*}{$\begin{array}{l}\text { OUTPUT } \\
\text { (thousands } \\
\mathrm{m}^{3} \text { ) }\end{array}$} & UK & 7 & $7,587,792$ & $2,242,947$ & $5,587,123$ & $12,047,916$ \\
\hline & $\mathrm{NL}$ & 21 & 713,840 & 718,633 & 66,958 & $2,460,579$ \\
\hline & SLO & 14 & 20,426 & 23,735 & 621 & 69,173 \\
\hline & Total & 42 & $1,628,361$ & $2,891,891$ & 621 & $12,047,916$ \\
\hline \multirow{4}{*}{$\begin{array}{l}\text { PEAK } \\
\left(\mathrm{m}^{3} / \text { day }\right)\end{array}$} & UK & 7 & $48,977,331$ & $13,356,546$ & $32,031,755$ & $75,879,258$ \\
\hline & $\mathrm{NL}$ & 21 & $5,261,354$ & $5,610,676$ & 451,900 & $17,311,908$ \\
\hline & SLO & 14 & 123,609 & 142,013 & 4,706 & 486,327 \\
\hline & Total & 42 & $10,834,768$ & $18,572,700$ & 4,706 & $75,879,258$ \\
\hline \multirow{4}{*}{$\begin{array}{l}N E T \\
(\mathrm{~km})\end{array}$} & UK & 7 & 30,653 & 8,819 & 22,512 & 46,619 \\
\hline & $\mathrm{NL}$ & 21 & 3,718 & 4,085 & 315 & 17,403 \\
\hline & SLO & 14 & 159 & 168 & 9 & 491 \\
\hline & Total & 42 & 7,021 & \begin{tabular}{|l|}
11,685 \\
\end{tabular} & 9 & 46,619 \\
\hline
\end{tabular}

Table 1: Descriptive statistics of the variables included in the analysis 
4. peak demand (PEAK, in $\mathrm{m}^{3} /$ day); and

5. network length (NET, in $\mathrm{km}$ ).

The descriptive statistics in Table 1 show some considerable size differences between the utilities. UK utilities are the largest in size, followed by their Dutch and Slovenian counterparts. In order to ensure comparable data on operating expenditure (OPEX) for gas distribution utilities from Slovenia, the Netherlands and the UK, some of the figures had to be appropriately adjusted.

The OPEX data on Slovenian gas distribution utilities were gathered from the income statements of distribution companies. In the past, regulation of gas distribution companies in Slovenia was assigned to local planning authorities. Thus, at a state level, the market for natural gas was less regulated than the electricity market. Another reason for less extensive regulation in gas was the principle of negotiated thirdparty access introduced by the Energy Act of 1999 . Through an Amendment to the Energy Act in 2004, regulated third-party access and the legal separation of distribution system operation from supply activities were introduced (AERS 2005a). However, since the framework prices for the use of distribution network have only recently been set by the Slovenian energy regulator, we were unable to obtain separate distribution and retail cost data. The Slovenian OPEX data thus include supply costs, operation and maintenance costs related to gas distribution networks, labour costs, overheads, and metering costs. Annual depreciation and gas purchasing costs were excluded from OPEX.

Comparable data on operating expenditure for Dutch utilities was obtained from the Dutch energy regulator DTE (2001). UK and Slovenian OPEX data are given for 2003, while Dutch data were only available for 1999 . Thus, they had to be adjusted for both the inflation rate and for improved network efficiency over the relevant regulatory period. Adjustments to the 2003 level were made by rescaling costs down in accordance with the final CPI-X formula as applied to the Dutch gas utilities by DTE. This might provide non-Dutch companies with a benchmarking advantage if the Dutch companies managed to undercut the CPI-X price control between 2000 and 2003. The Dutch regulator separates operating (OPEX) and capital expenditure (CAPEX) for accounting purposes, but applies total cost (TOTEX) benchmarking. In the Netherlands, there is already unbundling of network and supply OPEX in place and separate regulation for each. Since in 2003 such a split was not yet in place for Slovenia, benchmarking had to be conducted for the total of network and supply OPEX. Therefore, for the purpose of this benchmark, OPEX items for network and supply activities were summed up.

OPEX data for UK utilities was provided by the UK regulator OFGEM. The basic principle for establishing the OPEX split for UK distribution companies is the methodology developed by the UK gas transmission system operator NGT (formerly Transco) in agreement with the British regulator OFGEM as part of the process for the sale of up to four Distribution Networks by Transco in 2004. The methodology utilised by Transco allocates direct and indirect costs between the eight Distribution Networks. OPEX relates to the gas network only and does not include supply and metering costs. The basis for determining the cost of gas supply is a combination of OFGEM's (2004) analysis of the costs associated with the supply of gas to household (domestic) customers and the analysis of the financial accounts of Centrica plc for the period ending 31 December 2003 with respect to the costs they incur when supplying gas to their customers. ${ }^{\text {xii }}$ The abovementioned OFGEM analysis was also the basis for estimating metering costs.

\section{Model specification}

The technology of network services is difficult to model. There is a general agreement with Neuberg (1977) on the four main factors that affect the cost of electricity (and gas) distribution: energy throughput, the number of customers/connections, network length, and the area of supply. On the other hand, there is no consensus in the literature on how to treat capital. Some authors consider it endogenous, while others consider it exogenous. The length of distribution pipes, for example, may be considered an input, but it may be affected by the location of customers (output), which is not controllable in the 


\begin{tabular}{|c|c|c|}
\hline \multicolumn{3}{|c|}{ Variables } \\
\hline Input & Output & Environmental ${ }^{1}$ \\
\hline $\begin{array}{l}\text { - number of } \\
\text { employees } \\
\text { - network length } \\
(\mathrm{km}) \\
\text { - transformer } \\
\text { capacity (MVA) } \\
\text { - OPEX (PPP) } \\
\text { - TOTEX (PPP) } \\
\text { - controllable } \\
\text { OPEX (PPP) }\end{array}$ & $\begin{array}{l}\text { - number of } \\
\text { customers } \\
\text { - total energy } \\
\text { delivered (GWh, } \\
\mathrm{m}^{3} \text { ) } \\
\text { - residential sales } \\
\left(\mathrm{GWh}, \mathrm{m}^{3}\right) \\
\text { - non-residential } \\
\left.\text { sales (GWh, } \mathrm{m}^{3}\right) \\
\text { - service area (km²) } \\
\text { - maximum (peak) } \\
\text { demand (MW, } \\
\mathrm{m}^{3} / \text { day) } \\
\text { - network length } \\
\text { (km) }\end{array}$ & $\begin{array}{l}\text { - network length } \\
\text { - service area } \\
\text { - maximum demand } \\
\text { - transformer capacity } \\
\text { - residential sales } \\
\text { - non-residential sales } \\
\text { - share of residential } \\
\text { sales } \\
\text { - customer density (per } \\
\text { km²) } \\
\text { - network mix } \\
\text { - customer mix } \\
\text { - distribution losses } \\
\text { (GWh, m³) } \\
\text { - GNP per capita (PPP) }\end{array}$ \\
\hline
\end{tabular}

${ }^{1}$ Different models include different assumptions about environmental variables.

${ }^{2}$ Applies to electricity distribution only.

Table 2: Variables employed in benchmarking studies of electricity and gas distribution companies

short run and may be subject to a universal service obligation to supply. ${ }^{\text {iii }}$ With respect to the other outputs, single-variable measures such as either total gas delivered or the number of customers can be chosen. Nevertheless, many researchers prefer multiple outputs. Table 2 provides the list of variables commonly employed in the international benchmarking studies. In some cases, physical measures of inputs as proxies for operating and capital costs are used. However, the primary aim of regulators when using benchmarking is to promote cost savings in the utilities that result in lower prices for final users. From this point of view, cost-based benchmarking should be preferred (Jamasb and Pollitt 2001).

The findings of the literature review presented in Table 2 served as a starting point in constructing our model. To test for the sensitivity of the results with respect to the different variables included in the model, we decided to calculate efficiency scores for various model specifications, as shown in Table 3. We applied the DEA method in an input-minimising mode with both constant and variable returns to scale (CRS and VRS specification). Since very high correlation between the variables OUTPUT and PEAK was discovered, the two variables are not jointly included in any of the specified models. . $^{\text {iv }}$
The models specified in Table 3 allow us to obtain cost efficiency scores. By conducting constant and variable returns to scale analyses, scale efficiency scores can be obtained residually. Since we do not have separate data on input prices and input quantities, it is not possible to disentangle cost (overall) efficiency into technical and allocative efficiency components.

\section{Results}

OPEX DEA was run with DEA Excel Solver by J. Zhu (2003). Average cost efficiency scores from the three countries considered are reported in Table 4. The cost efficiency scores obtained from all five DEA CRS models put companies from mature regulatory environments at an advantage, apparently marking out a difference between Slovenia and the two older EU member states. The average efficiency of UK gas distribution utilities is $77.7 \%$, which is slightly higher than the $73.1 \%$ efficiency level reported for Dutch utilities. One out of the five models actually favours Dutch companies, but the differences are negligible. Average sample efficiency is $60.4 \%$. Slovenian utilities, with an average efficiency score of $32.6 \%$, are clearly lagging behind.

DEA VRS models concede that the companies need not necessarily be operating at the optimal scale of

\begin{tabular}{|l|c|c|c|c|c|}
\hline Variable & $\begin{array}{c}\text { Model } \\
\mathbf{1}\end{array}$ & $\begin{array}{c}\text { Model } \\
\mathbf{2}\end{array}$ & $\begin{array}{c}\text { Model } \\
\mathbf{3}\end{array}$ & $\begin{array}{c}\text { Model } \\
\mathbf{4}\end{array}$ & $\begin{array}{c}\text { Model } \\
\mathbf{5}\end{array}$ \\
\hline OPEX & $\mathrm{I}$ & $\mathrm{I}$ & $\mathrm{I}$ & $\mathrm{I}$ & $\mathrm{I}$ \\
\hline CUST & $\mathrm{O}$ & $\mathrm{O}$ & $\mathrm{O}$ & $\mathrm{O}$ & $\mathrm{O}$ \\
\hline OUTPUT & $\mathrm{O}$ & & $\mathrm{O}$ & $\mathrm{O}$ & \\
\hline PEAK & & $\mathrm{O}$ & & & $\mathrm{O}$ \\
\hline NET & & $\mathrm{O}$ & $\mathrm{NI}$ & $\mathrm{NI}$ \\
\hline
\end{tabular}
$\begin{aligned} & \text { Legend: } \\
& \text { - input variable - output variable } \\
& \text { NI-non-discretionary input (environmental variable) }\end{aligned}$

Table 3: DEA models used 


\begin{tabular}{|l|l|r|r|c|}
\hline \multicolumn{1}{|c|}{ Efficiency scores } & UK & Netherlands & \multicolumn{1}{c|}{ Slovenia } & \multicolumn{1}{c|}{ Total } \\
\hline CE_crs1 & 0.715 & 0.702 & 0.282 & 0.564 \\
\hline CE_crs2 & 0.713 & 0.688 & 0.235 & 0.541 \\
\hline CE_crs3 & 0.715 & 0.723 & 0.462 & 0.635 \\
\hline CE_crs4 & 0.873 & 0.769 & 0.351 & 0.647 \\
\hline CE_crs5 & 0.870 & 0.771 & 0.303 & 0.632 \\
\hline CE_vrs1 & 0.973 & 0.753 & 0.455 & 0.690 \\
\hline CE_vrs2 & 0.960 & 0.721 & 0.415 & 0.659 \\
\hline CE_vrs3 & 0.977 & 0.786 & 0.522 & 0.730 \\
\hline CE_vrs4 & 0.975 & 0.801 & 0.523 & 0.737 \\
\hline CE_vrs5 & 0.962 & 0.791 & 0.483 & 0.717 \\
\hline CE_crs_average & 0.777 & 0.731 & 0.326 & 0.604 \\
\hline CE_vrs_average & 0.969 & 0.770 & 0.480 & 0.707 \\
\hline
\end{tabular}

scale

efficiency, respectively. Apparently, Dutch utilities are operating very close to the optimal size, while, on the other hand, Slovenian utilities are too small to fully exhaust economies of scale and UK utilities appear to be too big and are found to operate in the region where returns to scale

Table 4: Average DEA cost efficiency scores using CRS and VRS specification are already decreasing. activity. As a result, each company is compared only with other companies of a similar size. Due to the considerable size differences in our sample, the VRS assumption seems to be plausible. By construction, DEA VRS models display higher efficiency scores, with an average sample efficiency of $70.7 \%$. However, both DEA versions arrive at similar conclusions with regard to country performance. Once again, UK utilities, with a cost efficiency of $97 \%$, prove to be the most efficient on average. They are followed by Dutch

\begin{tabular}{|l|c|c|c|c|}
\hline \multicolumn{1}{|c|}{$\begin{array}{c}\text { Efficiency } \\
\text { scores }\end{array}$} & UK & Netherlands & Slovenia & Total \\
\hline$S E_{-}$1 & 0.735 & 0.932 & 0.620 & 0.817 \\
\hline$S E_{2}$ & 0.742 & 0.954 & 0.566 & 0.821 \\
\hline$S E_{-} 3$ & 0.731 & 0.921 & 0.885 & 0.870 \\
\hline$S E_{-} 4$ & 0.896 & 0.959 & 0.670 & 0.877 \\
\hline$S E_{\text {_5 }}$ & 0.904 & 0.975 & 0.627 & 0.881 \\
\hline SE_average & 0.802 & 0.948 & 0.674 & 0.853 \\
\hline
\end{tabular}

Table 5: Average DEA scale efficiency scores

utilities, with an average cost efficiency score of $77 \%$. Slovenian firms again prove to be the least efficient ones and could, on average, theoretically produce the same output level at $48 \%$ of their current operating costs. All five DEA VRS models produce very similar results by country.

The difference between the average CRS and VRS cost efficiency scores is ascribed to scale efficiency. The results on average scale efficiency for the three countries are reported in Table 5. The scale efficiency scores are obtained residually from the reported CRS and VRS cost efficiency scores. With an average scale efficiency score of $94.8 \%$, Dutch utilities are found to be the most scale efficient. They are followed by UK and Slovenian utilities with $80.2 \%$ and $67.4 \%$ average
The low efficiency scores of Slovenian gas distribution utilities can be explained by the fact that, in the past, gas distribution utilities were controlled by local planning authorities and faced no explicit efficiency 
establish the conditions in which frontier benchmarking techniques are most useful to regulatory authorities, Bauer et al. (1998) defined a set of consistency conditions that, if met, would make the choice of a particular method trivial. The efficiency scores obtained by different techniques should be consistent in their efficiency levels, rankings, and identification of the best and worst performers. However, in the absence of any consensus on the most appropriate technique to use, model specification, and variables, a purely practical approach would entail the combination of results from different models. In this case, benchmarking should only be used as a complementary instrument in price-cap regulation, and not as the regulator's main tool.

Our sample shows that the different models applied yield quite similar results with respect to relative efficiency scores. All models identify the same best practice, while in the case of 'worst practice' we get different results. The correlation matrix between cost efficiency ranks obtained from the different models is given in Table 6 . The results indicate a relatively high correlation between the rank orders produced by the models. Nevertheless, the established consistency of efficiency scores is only based on the results of the DEA method. As already pointed out, in a number of studies it was found that benchmarking is, to a certain extent, influenced by the techniques chosen, model specification, and variables included in the model. Therefore, rather than using efficiency estimates in a mechanistic way, regulators are advised - and are increasingly becoming aware of this issue - to use benchmarking as one of the instruments for price regulation purposes.

\section{Conclusions}

This paper carried out a relative efficiency comparison of gas distribution utilities from two 'older' European Union countries and one newcomer. We used nonparametric benchmarking analysis (DEA) to assess an international cross-section of gas utilities subject to economic regulation in their respective countries. DEA cost efficiency results show that Slovenian gas distribution utilities perform, on average, less efficiently than their UK and Dutch counterparts. This suggests the presence of an efficiency gap between two old and one new EU member countries. The regulatory reforms recently introduced in Slovenia aim to raise the performance of gas distributors. UK utilities are found on average to be the most cost efficient, whereby the differences with the Dutch distributors are small when constant returns to scale are assumed, while the variable returns to scale assumption results in somewhat more striking differences. On the other hand, Dutch utilities are found to operate very close to the optimal size and thus outperform the UK utilities with respect to the scale efficiency. Reassuringly, different model specifications lead to relatively stable efficiency scores and rankings. Nevertheless, regulatory authorities are not encouraged to use benchmarking as their main instrument for monitoring utilities' performance, ase benchmarking can be influenced by the variables, model specification, and methodology

\begin{tabular}{|c|c|c|c|c|c|c|c|c|c|c|}
\hline & $R \_$crs 1 & $R_{-} \operatorname{crs} 2$ & $R_{-} \operatorname{crs} 3$ & $R_{-} \mathrm{crs} 4$ & $R_{-} \operatorname{crs} 5$ & R_vrs1 & $R_{-}$vrs2 & $R_{\text {_ vrs3 }}$ & $R \_v r s 4$ & $R \_$vrs5 \\
\hline$R \_c r s 1$ & 1.000 & 0.922 & 0.853 & 0.852 & 0.797 & 0.732 & 0.653 & 0.711 & 0.676 & 0.628 \\
\hline$R_{-} \mathrm{crs} 2$ & & 1.000 & 0.780 & 0.781 & 0.850 & 0.680 & 0.749 & 0.666 & 0.612 & 0.676 \\
\hline$R_{-} \operatorname{crs} 3$ & & & 1.000 & 0.672 & 0.620 & 0.778 & 0.705 & 0.806 & 0.678 & 0.632 \\
\hline$R_{-}$crs 4 & & & & 1.000 & 0.938 & 0.632 & 0.557 & 0.550 & 0.809 & 0.780 \\
\hline$R_{-} \operatorname{crs} 5$ & & & & & 1.000 & 0.572 & 0.619 & 0.490 & 0.748 & 0.833 \\
\hline R_vrs1 & & & & & & 1.000 & 0.896 & 0.939 & 0.868 & 0.776 \\
\hline$R_{-}$vrs2 & & & & & & & 1.000 & 0.849 & 0.759 & 0.823 \\
\hline$R \_$vrs3 & & & & & & & & 1.000 & 0.766 & 0.674 \\
\hline$R_{-}$vrs4 & & & & & & & & & 1.000 & 0.920 \\
\hline$R \_$vrs5 & & & & & & & & & & 1.000 \\
\hline
\end{tabular}

All correlation coefficients are significant at the 0.01 level (2-tailed significance level).

Table 6: Correlation coefficients between cost efficiency ranks given by different DEA CRS and VRS specifications 
employed. Benchmarking can, however, be viewed as an extremely effective complementary regulatory instrument.

Gas networks used to be regulated in the past without any explicit reference to economic benchmarking, mainly because of the lack of reliable technical and cost data, coupled with a sometimes strong opposition from private-sector industry lobbies. Thanks to benchmarking analysis, the information asymmetry traditionally observed between utilities and regulatory authorities can be mitigated. By aiming at fairly exposing individual strengths and weaknesses to the scrutinising power of data comparisons, international benchmarking can therefore be used to assess gas companies running distribution as a territorial monopoly in their respective regions. Our study is one of the first contributions to international gas benchmarking as opposed to the more explored electricity sector. It is also one of the first studies on relative performance of gas distribution utilities from Central and Eastern European (ex-)transition countries. The study provides an important indication on the presence of a significant performance gap between the companies from the new and the old EU member states and specifies the need to introduce incentivebased price cap regulation of gas distribution companies. For the wider and more successful implementation of international benchmarking in the future, it is of paramount importance to ensure the provision of harmonised regional and international data to national and international regulators, along with the full integration of European datasets. Cooperation between regulators would relax certain limitations of the analysis related to data comparability, availability and small sample size. In the presence of large samples, the study could be further improved by the use of alternative parametric frontier methods (e.g., SFA). All of this would in turn contribute to improved reliability of efficiency results which is of paramount importance if the results are to be used in economic policy-making. $[$.

\section{References}

Amendments to the Energy Act 2004. Official Gazette of the Republic of Slovenia 51/04, Ljubljana.
AERS (Energy Agency of the Republic of Slovenia) 2005a. Report on the Energy Sector for 2004. Maribor.

AERS 2005b. Regulations on the Methodology for Setting the Network Charge and Defining the Criteria for Establishing the Eligible Costs for Gas Distribution Network (Akt o določitvi metodologije za določitev omrežnine in kriterijev za ugotavljanje upravičenih stroškov za distribucijsko omrežje zemeljskega plina). Official Gazette of the Republic of Slovenia, 87/2005, Ljubljana.

Banker, R.D., Charnes, A., Cooper, W.W. 1984. Some models for estimating technical and scale inefficiencies in data envelopment analysis. Management Science 30(9): 1078-1092.

Bauer, P., Berger, A., Ferrier, G., Humphrey, D. 1998. Consistency Conditions for Regulatory Analysis of Financial Institutions: A Comparison of Frontier Efficiency Methods. Journal of Economics and Business 50: 85-114.

Charnes, A., Cooper, W.W., Rhodes, E. 1978. Measuring the efficiency of decision-making units. European Journal of Operational Research 2: 429-444.

Coelli, T.J., Rao, P.D.S., Battese G.E. 1998. An Introduction to Efficiency and Productivity Analysis. Kluwer Academic Publishers.

Cooper, W.W., Seinford, M.L., Tone, K. 2003. Data Envelopment Analysis. Kluwer Academic Publishers.

Debreu, G. 1951. The Coefficient of Resource Utilisation. Econometrica 19: 225-234.

Directive 98/30/EC of the European Parliament and of the Council of 22 June 1998 Concerning Common Rules for the Internal Market in Natural Gas. OJ L 204/1.

Directive 2003/55/EC of the European Parliament and of the Council of 26 June 2003 Concerning Common Rules for the Internal Market in Natural Gas and Repealing Directive 98/30/EC. OJ L 176/57.

DTE (Dienst uitvoering en toezicht Energie) 2001. Price-cap regulering gasdistributiebedrijven 2002/2003 [Price-Cap Regulation, Gas Distribution Companies 2002/2003]. Consultation document. The Hague.

Dyson, R. G., Allen, R. Camanho, A. S., Podinovski, V. V., Sarrico, C. S., Shale, E. A. 2001. Pitfalls and protocols in DEA. European Journal of Operational Research 132(2): 245-259.

Estache, A., Rossi, M.A., Ruzzier, C.A. 2004. The Case of International Coordination of Electricity Regulation: Evidence from Measurement of Efficiency in South America. Journal of Regulatory Economics 25 (3): 271-295.

Energy Act 1999. Official Gazette of the Republic of Slovenia 79/99, Ljubljana.

Fare, R., Grosskopf, S., Lovell, C.A.K. 1985. The Measurement of the Efficiency of Production. Boston (MA), Kluwer Academic Publishers.

Farrell, M.J. 1957. The Measurement of Productive Efficiency. Journal of the Royal Statistical Society, Series A, 120: 253-281. 
Farsi, M. and Filippini, M. 2004. Regulation and measuring cost efficiency with panel data models: application to electricity distribution utilities. The Review of Industrial Organization 25: 1-19.

Farsi, M. Filippini, M. and Greene, W. 2005. Efficiency Measurement in Network Industries: Application to the Swiss Railway Companies. Journal of Regulatory Economics 28(1): 69-90.

Hattori, T. 2002. Relative performance of U.S. and Japanese Electricity Distribution: An Application of Stochastic Frontier Analysis. Journal of Productivity Analysis 18, 269-284.

Hattori, T., Jamasb, T., Pollitt, M. 2002. A comparison of UK and Japanese electricity distribution performance, 1985-1998: lessons for incentive regulation. DAE Working Paper 0212. Department of Applied Economics, University of Cambridge.

Hrovatin, N. and Švigelj, M. 2004: Analysis of the natural gas price setting system for tariff customers in Slovenia. Economic and Business Review for Central and South-Eastern Europe 6(1): 69-87.

Hrovatin, N., Zorić, J., Scarsi, G.C., Paripovič, M., Senčar, M. 2005. The relative performance of electricity distribution utilities from Slovenia, the Netherlands and the UK: an application of Data Envelopment Analysis. Economic and Business Review for Central and SouthEastern Europe 7(4): 329-349.

IPART 1999. Efficiency Benchmarking Study of the NSW Distribution Business. Research Paper No. 13. Commissioned by the Independent Pricing and Regulatory Tribunal of New South Wales, Sydney.

Jamasb, T. and Pollitt, M. 2001. Benchmarking and regulation: international electricity experience. Utilities Policy 9: 107-130.

Jamasb, T. and Pollitt, M. 2003. International benchmarking and regulation: an application to European electricity distribution utilities. Energy Policy 31(15): 1609-1622.

Joskow, P. J. and Schmalensee, R. 1986. Incentive regulation for electric utilities, Yale Journal on Regulation 4: 1-49.

Koopmans, T.C. 1951. An Analysis of Production as an Efficient Combination of Activities, in: Koopmans, T.C. (Ed.), Activity Analysis of Production and Allocation. Cowles Commission for Research in Economics, Monograph 13. New York: Wiley.

Kumbhakar, S. C. and Lovell, C.A.K. 2000. Stochastic Frontier Analysis. Cambridge University Press.

National Grid Transco (NGT) 2005. Annual Report and Accounts 2004/05. Available at www.investis.com/ngt/ara_2005/ofr_ukgd.html.

Neuberg, L.G. 1977. Two Issues in the Municipal Ownership of Electric Power Distribution Systems. Bell Journal of Economics 8: 303323.

Office of Gas and Electricity Markets (OFGEM) 2004. Domestic Competitive Market Review. Available at www.ofgem.gov.uk.

Pardina, M.R. and Rossi, M.A. 2000. Technical change and catchingup: the electricity distribution sector in South America. CEER, Departamento de Economia y Finanzas, Universidad de la Empresa, Buenos Aires.
Pollitt, M. 1994. Productive efficiency in electricity transmission and distribution systems. Applied Economics Discussion Paper Series No. 161. Institute of Economics and Statistics, University of Oxford.

Zhu, J. 2003. Quantitative Models for Performance Evaluation and Benchmarking. Data Envelopment Analysis with Spreadsheets and DEA Excel Solver. Boston (MA), Kluwer Academic Publishers.

\section{Endnotes}

i For a general discussion of these models, see Joskow and Schmalensee (1986). For an overview of the main benchmarking methods used in the OECD and a few other countries, see Jamasb and Pollitt (2001)

ii A number of empirical studies with a cross-country focus have addressed the issue of relative efficiency and performance, e.g.: Pollitt (1994), IPART (1999), Jamasb and Pollitt (2003), Hattori (2002), Hattori, Pardina and Rossi (2000), Estache, Rossi and Ruzzier (2004), and Hrovatin et al. (2005). However, such studies focussed on the electricity sector.

iii The Slovenian market heavily depends on imports since Slovenia produces negligible quantities of natural gas. Geoplin imports natural gas from three sources (Russia, Algeria, and Austria) on the basis of long-term take-or-pay contracts.

iv The majority of local distribution utilities are, besides natural gas distribution, also engaged in other activities such as district heating, water supply, etc.

${ }^{\vee}$ Large industrial customers, power generation utilities, non-energy users, local distribution, and district heating utilities are supplied directly via the transport/transmission system, while small industrial customers, commercial users, and households are supplied via local distribution networks.

vi However, most eligible customers still have long term contracts with Geoplin, which will expire partially in 2007 and in 2010. These contracts prevent them from purchasing natural gas on the open market (Hrovatin and Švigelj 2004).

vii The envelopment model is a corresponding dual problem of the multiplier model, i.e. the primal problem (Cooper, Seinford and Tone 2003). Since the envelopment form involves fewer constraints than the multiplier form $(K+M<N+1)$, it is usually the preferred form to solve.

viii Separability may also be exploited in order to decompose technical efficiency into scale, congestion, and 'pure' technical efficiency as in Fare, Grosskopf and Lovell (1985).

${ }^{i x}$ For SFA methods, a good reference is Kumbhakar and Lovell (2000).

x For example, see Bauer et al. (1998), Estache, Rossi and Ruzzier (2004), Farsi and Filippini (2004), Jamasb and Pollitt (2003), and Farsi, Filippini and Greene (2005).

${ }^{x i}$ Due to missing data, four companies from the Netherlands and one company each from the UK and Slovenia had to be excluded from the sample.

xii Centrica plc (retailing as British/Scottish Gas) is the largest retail supplier of gas in the UK.

xiii As far as electricity distribution is concerned, Pollitt (1994), IPART (1999), and Estache, Rossi and Ruzzier (2004) treat line length as an input, while Jamasb and Pollitt (2003) and some regulators use line length as an output.

xiv Dyson et al. (2001) for example suggests that dropping a strongly correlated variable may significantly influence efficiency results.

${ }^{x v}$ The distribution of natural gas in Slovenia is a local optional, not a national and universal public service. This is in stark contrast to electricity distribution, which is mandatory and a nationwide recognised public service. In some other countries, universal service obligations are enforced on both sectors.

xvi For example, see Estache, Rossi and Ruzzier (2004), and Farsi and Filippini (2004) 